\title{
COLOUR DOPPLER EVALUATION IN HIGH-RISK PREGNANCY AND PERINATAL OUTCOME
}

\author{
Harshika Singh1, Manjusha Agrawal2, Arvind Bhake3, Nihar Gupta ${ }^{4}$
}

${ }_{1}^{1}$ Resident, Department of Obstetrics and Gynaecology, Jawaharlal Nehru Medical College, DMIMS (DU), Sawangi (M), Maharashtra, India.

2Professor, Department of Obstetrics and Gynaecology, Jawaharlal Nehru Medical College, DMIMS (DU), Sawangi (M), Maharashtra, India.

3 Professor and HOD, Department of Pathology, Jawaharlal Nehru Medical College, DMIMS (DU), Sawangi (M), Maharashtra, India. ${ }^{4}$ Resident, Department of Pathology, Jawaharlal Nehru Medical College, DMIMS (DU), Sawangi (M), Maharashtra, India.

\section{ABSTRACT}

\section{BACKGROUND}

Doppler velocimetry is a rapid non-invasive test that provides valuable information about haemodynamic situation of the foetus and is an efficient diagnostic test of foetal jeopardy, which helps in timely intervention and management of high-risk pregnancy for better perinatal outcome.

Objectives:

1. To assess the role of Colour Doppler imaging in prediction of high-risk pregnancies and their perinatal outcome.

2. To evaluate the role of Colour Doppler in normal and high-risk pregnancies in relation to perinatal outcome.

\section{MATERIALS AND METHODS}

The present study was carried out as a prospective observational study. The study was carried out from 1st August 2016 to 31 st July 2018 in Department of Obstetrics and Gynaecology in co-ordination with Central Laboratory and Department of Radiology, Jawaharlal Nehru Medical College, Sawangi (M), Wardha, Maharashtra. A total of 120 pregnant women (study group and control group) attending a clinic in Dept. of Gynaecology and Obstetrics, AVBRH was examined for high-risk pregnancy.

\section{RESULTS}

There was a significant difference between the Colour Doppler indices of the three vessels (Umbilical, Uterine and Middle Cerebral Artery) in the study and the control groups. In women with abnormal Doppler indices, there was a high incidence of caesarean section, low birth weight babies, low Apgar score and higher admission rate to NICU.

\section{CONCLUSION}

The Colour Doppler findings with abnormal indices of Uterine artery, Umbilical artery and Middle cerebral artery shows consistent relationship with poor perinatal outcome.

\section{KEY WORDS}

High-Risk Pregnancy, Colour Doppler, Perinatal Outcome.

HOW TO CITE THIS ARTICLE: Singh H, Agrawal M, Bhake A, et al. Colour Doppler evaluation in high-risk pregnancy and perinatal outcome. J. Evolution Med. Dent. Sci. 2018;7(43):4603-4608, DOI: 10.14260/jemds/2018/1027

\section{BACKGROUND}

High-risk pregnancy group are categories of pregnancies where the mother, the foetus or the neonate is in state of increased jeopardy. About $20-30 \%$ of the pregnancies belong to this category. To improve the obstetric result, this group must be identified and given extra care. Even with the adequate antenatal and intranatal care, this small group is responsible for $70-80 \%$ of perinatal mortality and morbidity.(1)The principle of Doppler ultrasound was described in 1842 by Johann Christian Doppler. Identification of the pregnancies at risk for preventable perinatal morbidity and mortality is a primary goal of the obstetric care.(2) The development of Doppler ultrasound evaluation of uteroplacental and foetoplacental circulation is one of the most important achievements of modern obstetrics.

'Financial or Other Competing Interest': None.

Submission 03-09-2018, Peer Review 01-10-2018,

Acceptance 09-10-2018, Published 22-10-2018.

Corresponding Author:

Dr. Manjusha Agrawal,

Sawangi (M), Wardha, Maharashtra, India.

E-mail: badnemanju@gmail.com, toshi.singh.23@gmail.com DOI: $10.14260 /$ jemds $/ 2018 / 1027$
Doppler velocimetry is a rapid non-invasive test that provides valuable information about haemodynamic situation of the foetus and is an efficient diagnostic test of foetal jeopardy that helps in management of high-risk pregnancy. (3)

Doppler techniques have been the focus of interest and research activity in obstetrics, since the initial report of signals from the umbilical artery by Fitzgerald and Drumm.(4) The first application of Doppler velocimetry in obstetrics was reported by Fitzgerald and Drumm and McCallum et al.(5) It has been long assumed that insufficient uterine, placental and foetal circulations result in adverse pregnancy outcomes and that those abnormalities can be detected by the use of Doppler ultrasonography. ${ }^{(6)}$

Elevated impedance to blood flow in the placenta is reflected by abnormal umbilical artery velocimetry.(7) Absence or reversal of end-diastolic flow in the Umbilical Artery (UA) is suggestive of poor foetal condition.(8) Foetal middle cerebral arterial Doppler assessment plays an important role in determining cardiovascular distress, foetal anaemia or foetal hypoxia. The uterine artery Doppler waveform is unique and increased resistance to flow and development of a diastolic notch has been associated with high-risk pregnancy.(3)

The study was conducted with the aims to assess the role 
of colour Doppler imaging in prediction of high-risk pregnancies and their perinatal outcome and objectives to demonstrate the flow patterns and factors associated with adverse foetal outcome in high-risk pregnancy.

\section{MATERIALS AND METHODS}

The present study was carried out as a prospective observational study. This study was conducted in Department of Obstetrics and Gynaecology in Jawaharlal Nehru Medical College, Sawangi (M), Wardha, Maharashtra from 1st August 2016 to 31st July 2018. A total 204 cases, out of which 102 cases were of normal pregnancy and 102 cases were of highrisk pregnancy of $>32$ weeks of gestational age.

Each patient was subjected to a thorough history taking, general physical examination, systemic examination and obstetric examination. Then each patient was subjected to serial colour Doppler study, ultrasound examination and obstetrical examination. The colour Doppler study was carried out using Wipro GE Logiq F8 with curvilinear Colour Doppler machine; Sysmex Coulter Machine was used for complete blood counts, Randox Rx Imola machine for Liver and Kidney function test.

\section{Criteria for Selection}

Pregnancy with anaemia, PIH, bad obstetric history, Rh negative pregnancy, extreme age, $>32$ weeks of period of gestation, pregnant women with any of the above combinations.

\section{Interpretation of Doppler Finding}

1. Uterine artery having bilateral diastolic notch.

2. Umbilical artery S/D ratio of more than 3 or more than 95 percentile of reference values, PI more than 95 percentile of reference values or if diastolic flow was absent or reversed.

3. MCA PI less than lower limit of reference value.

Following Neonatal Information was Obtained-

1. Mode of delivery.

2. Indication of caesarean section.

3. Apgar score at 1 and 5 minutes.

4. Birth weight.

5. Admission to NICU.

6. Any intrauterine death or still birth.

\section{Statistical Analysis}

Statistical analysis was done by using descriptive and inferential statistics using Chi-square test and student's unpaired t-test and software used in the analysis were SPSS 22.0 version and GraphPad Prism 6.0 version and $p<0.05$ is considered as level of significance.

\section{RESULTS}

\begin{tabular}{|c|c|c|}
\hline High Risk Factors & Study Group & Percentage \\
\hline Pregnancy with anaemia & 19 & 18.63 \\
\hline $\begin{array}{c}\text { Pregnancy-induced } \\
\text { hypertension (PIH) }\end{array}$ & 27 & 26.47 \\
\hline $\begin{array}{c}\text { Pregnancy with Rh-ve blood } \\
\text { group }\end{array}$ & 10 & 9.80 \\
\hline Extreme age group & 0 & 0.00 \\
\hline
\end{tabular}

\begin{tabular}{|c|c|c|}
\hline Bad obstetric history (BOH) & 10 & 9.80 \\
\hline Rh -ve pregnancy with anaemia & 2 & 1.96 \\
\hline Rh -ve pregnancy with PIH & 5 & 4.90 \\
\hline Rh -ve pregnancy with BOH & 1 & 0.98 \\
\hline Extreme age group with PIH & 3 & 2.94 \\
\hline Bad obstetric history with PIH & 4 & 3.92 \\
\hline $\begin{array}{l}\text { Bad obstetric history with } \\
\text { anaemia }\end{array}$ & 3 & 2.94 \\
\hline PIH with anaemia & 17 & 16.67 \\
\hline $\begin{array}{l}\text { Anaemia with extreme age } \\
\text { group }\end{array}$ & 1 & 0.98 \\
\hline \multicolumn{3}{|c|}{$\begin{array}{c}\text { Table 1. Distribution of Cases according to High Risk } \\
\text { Factors }\end{array}$} \\
\hline
\end{tabular}

Table Number 1 shows distribution of cases according to high risk factors in pregnancy, in which out of total patients in high risk group (Study group) $26.47 \%$ patients belong to Pregnancy Induced Hypertension (PIH), 18.63\% patients belong to Pregnancy with anaemia, $16.67 \%$ patients belong to PIH with anaemia, 9.80\% patients belong to Pregnancy with Rh-ve blood group, 9.80\% patients belong to Bad Obstetric History (BOH), $4.90 \%$ patients belong to Rh-ve pregnancy with $\mathrm{PIH}, 3.92 \%$ patients belong to $\mathrm{BOH}$ with $\mathrm{PIH}, 2.94 \%$ patients belong to extreme age group with $\mathrm{PIH}, 2.94 \%$ patients belong to $\mathrm{BOH}$ with anaemia, $1.96 \%$ patients belong to $\mathrm{Rh}$-ve pregnancy with anaemia, $0.98 \%$ patients belong to Rh-ve pregnancy with $\mathrm{BOH}, 0.98 \%$ patients belong to anaemia with extreme age group and no patient in our study group had extreme age as the only high risk factor.

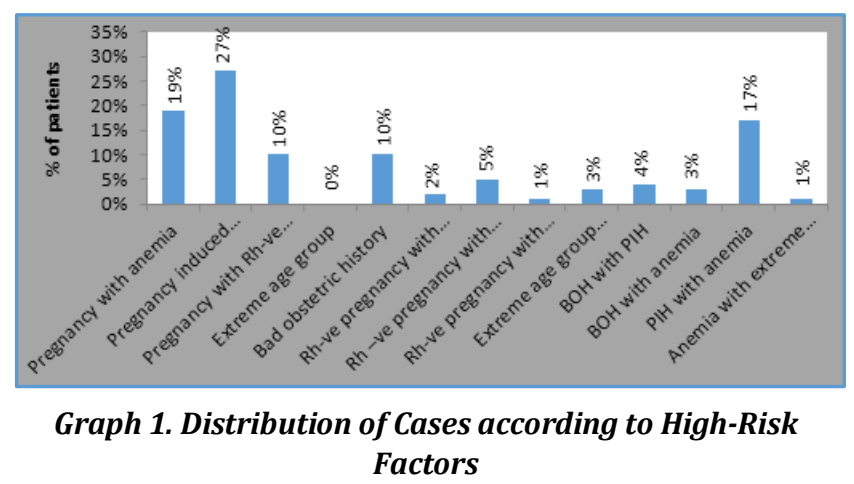

\begin{tabular}{|c|c|c|c|}
\hline $\begin{array}{c}\text { Gestational Age } \\
\text { (Weeks) }\end{array}$ & Study Group & Control Group & $\aleph 2$-value \\
\hline $32.0-34$ & $12(11.76 \%)$ & $7(6.86 \%)$ & \multirow{6}{*}{$\begin{array}{c}1.63 \\
p=0.44 \\
\text { NS }\end{array}$} \\
\hline $34.1-37$ & $57(55.88 \%)$ & $63(61.76 \%)$ & \\
\hline $37.1-41$ & $33(32.35 \%)$ & $32(31.37 \%)$ & \\
\hline Total & $102(100 \%)$ & $102(100 \%)$ & \\
\hline Mean \pm SD & $36.06 \pm 1.59$ & $36.36 \pm 1.26$ & \\
\hline Range & $32-40.60$ & $32-38.20$ & \\
\hline
\end{tabular}

Table 2. Distribution of Cases according to Gestational Age

Table Number 2 shows distribution of cases according to gestational age, in which $11.76 \%$ and $6.86 \%$ cases of study and control group respectively belong to gestational age of $32.0-34$ weeks, $55.88 \%$ and $61.76 \%$ cases of study and control group respectively belong to gestational age of 34.137 weeks, $32.35 \%$ and $31.37 \%$ cases of study and control group respectively belong to gestational age of 37.1-41 
weeks. The mean gestational age of study group is $36.06 \pm 1.59$ weeks, while of control group is $36.36 \pm 1.26$ weeks.

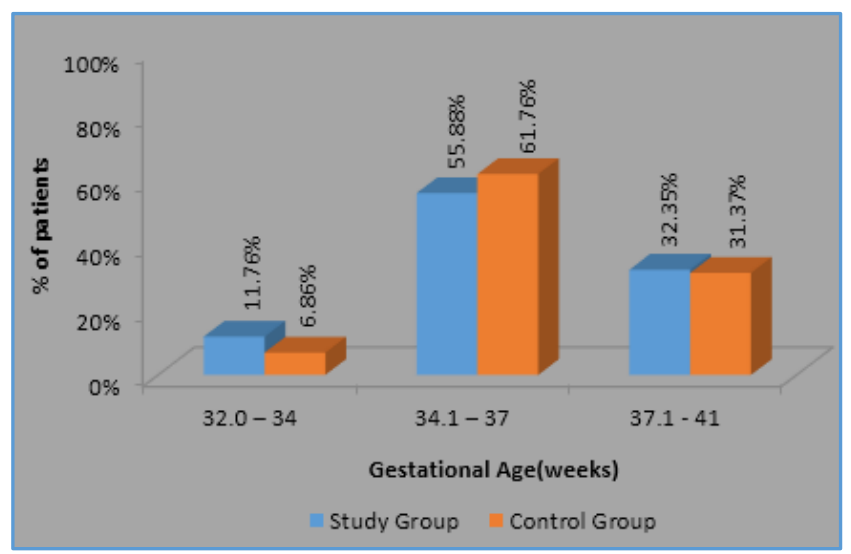

Graph 2. Distribution of Cases according to Gestational Age

\begin{tabular}{|c|c|c|c|}
\hline Hb gm\% & Study Group & Control Group & א2-value \\
\hline$<7$ & $3(2.94 \%)$ & $0(0 \%)$ & \multirow{7}{*}{$\begin{array}{c}30.68 \\
p=0.0001, S\end{array}$} \\
\hline $7-9$ & $21(20.59 \%)$ & $0(0 \%)$ & \\
\hline $9-11$ & $40(39.22 \%)$ & $38(37.25 \%)$ & \\
\hline$>11$ & $38(37.25 \%)$ & $64(62.72 \%)$ & \\
\hline Total & $102(100 \%)$ & $102(100 \%)$ & \\
\hline Mean \pm SD & $10.22 \pm 1.59$ & $11.24 \pm 0.82$ & \\
\hline Range & $6.20-14.40$ & $9.80-13.60$ & \\
\hline & $\begin{array}{r}\text { ribution of Ca } \\
\text { Ana }\end{array}$ & $\begin{array}{l}\text { s according to } \\
\text { ia }\end{array}$ & egree \\
\hline
\end{tabular}

Table Number 3 shows distribution of cases according to degree of anaemia, in which $2.94 \%$ and $0 \%$ cases of study and control group respectively belong to Haemoglobin range of below $7 \mathrm{gm} \%, 20.59 \%$ and $0 \%$ cases of study and control group respectively belong to Haemoglobin range of between 7-9 gm $\%, 39.22 \%$ and $37.25 \%$ cases of study and control group respectively belong to Haemoglobin range of between 9-11 gm $\%, 37.25 \%$ and $62.72 \%$ cases of study and control group respectively belong to Haemoglobin range of above 11 gm\%. The mean haemoglobin range of study group is $10.22 \pm 1.59 \mathrm{gm} \%$, while of control group is $11.24 \pm 0.82 \mathrm{gm} \%$.

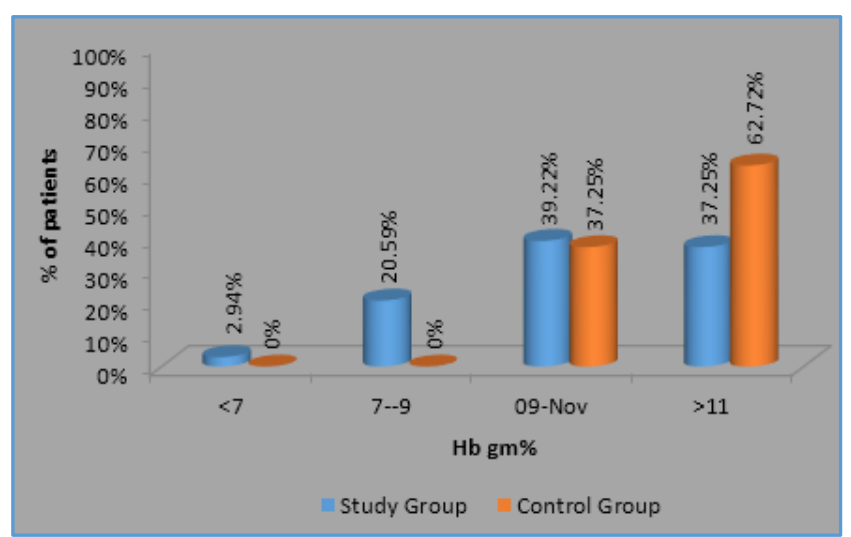

Graph 3. Distribution of Cases according to Degree of Anaemia

\begin{tabular}{|c|c|c|c|c|c|}
\hline & $\begin{array}{c}\text { Doppler } \\
\text { Indices }\end{array}$ & $\begin{array}{c}\text { Study } \\
\text { Group }\end{array}$ & $\begin{array}{c}\text { Control } \\
\text { Group }\end{array}$ & T-value & P-value \\
\hline \multirow{2}{*}{$\begin{array}{c}\text { Rt. } \\
\text { Uterine }\end{array}$} & S/D & $2.31 \pm 0.74$ & $1.39 \pm 0.58$ & 9.79 & $0.0001, \mathrm{~S}$ \\
\cline { 2 - 6 } & $\mathrm{RI}$ & $0.88 \pm 0.55$ & $0.48 \pm 0.12$ & 7.14 & $0.0001, \mathrm{~S}$ \\
\cline { 2 - 6 } & $\mathrm{PI}$ & $1.15 \pm 0.54$ & $0.86 \pm 0.55$ & 3.66 & $0.0001, \mathrm{~S}$ \\
\hline \multirow{2}{*}{$\begin{array}{c}\text { Lt. } \\
\text { Uterine }\end{array}$} & $\mathrm{S} / \mathrm{D}$ & $2.26 \pm 0.74$ & $1.54 \pm 0.67$ & 7.29 & $0.0001, \mathrm{~S}$ \\
\cline { 2 - 6 } & $\mathrm{RI}$ & $0.77 \pm 0.48$ & $0.54 \pm 0.19$ & 4.29 & $0.0001, \mathrm{~S}$ \\
\cline { 2 - 6 } & $\mathrm{PI}$ & $1.05 \pm 0.52$ & $0.88 \pm 0.57$ & 2.13 & $0.031, \mathrm{~S}$ \\
\hline
\end{tabular}

Table 4. Distribution of Cases according to Doppler Indices of Uterine Artery

Table Number 4 shows distribution of cases according to Doppler indices of Right and Left uterine artery. In right uterine artery, mean value of S/D of study and control group cases are $2.31 \pm 0.74$ and $1.39 \pm 0.58$ respectively. Mean value of RI of study and control group cases are $0.88 \pm 0.55$ and $0.48 \pm 0.12$ respectively. Mean value of PI of study and control group cases are $1.15 \pm 0.54$ and $0.86 \pm 0.55$ respectively. In left uterine artery mean value of S/D of study and control group cases are $2.26 \pm 0.74$ and $1.54 \pm 0.67$ respectively. Mean value of RI of study and control group cases are $0.77 \pm 0.48$ and $0.54 \pm 0.19$ respectively. Mean value of PI of study and control group cases are $1.05 \pm 0.52$ and $0.88 \pm 0.57$, respectively.

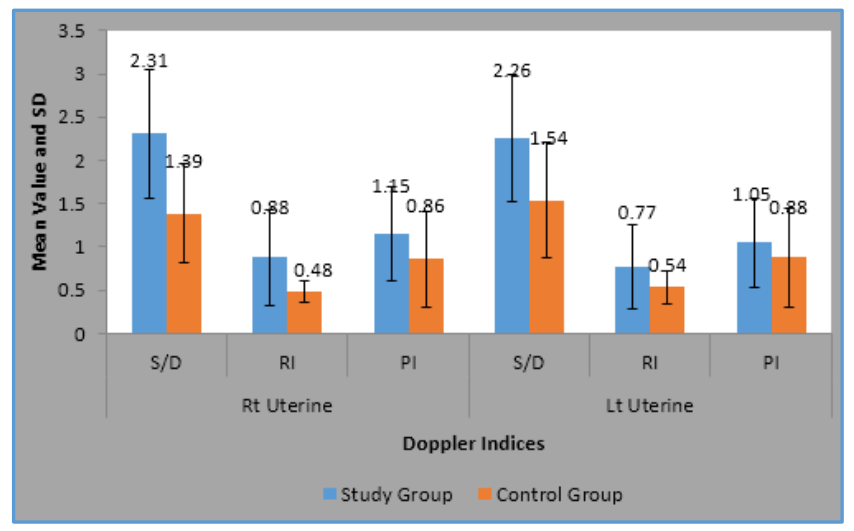

Graph 4. Distribution of Cases according to Doppler Indices of Uterine Artery

\begin{tabular}{|c|c|c|c|c|}
\hline $\begin{array}{c}\text { Doppler } \\
\text { Indices }\end{array}$ & $\begin{array}{c}\text { Study } \\
\text { Group }\end{array}$ & $\begin{array}{c}\text { Control } \\
\text { Group }\end{array}$ & T-value & P-value \\
\hline S/D & $2.65 \pm 1.14$ & $1.87 \pm 0.77$ & 5.74 & $\mathbf{0 . 0 0 0 1 , ~ S}$ \\
\hline RI & $0.74 \pm 0.27$ & $0.59 \pm 0.15$ & 4.75 & $\mathbf{0 . 0 0 0 1}, \mathbf{S}$ \\
\hline PI & $1.84 \pm 0.40$ & $1.23 \pm 0.78$ & 7.04 & $\mathbf{0 . 0 0 0 1 , S}$ \\
\hline Table 5. Distribution of Cases according to Doppler Indices \\
of Umbilical Artery \\
\hline
\end{tabular}

Table Number 5 shows distribution of cases according to Doppler indices of Umbilical artery, in which the mean value of S/D of study and control group cases are $2.65 \pm 1.14$ and $1.87 \pm 0.77$ respectively. Mean value of RI of study and control group cases are $0.74 \pm 0.27$ and $0.59 \pm 0.15$ respectively. Mean value of PI of study and control group cases are $1.84 \pm 0.40$ and $1.23 \pm 0.78$, respectively. 


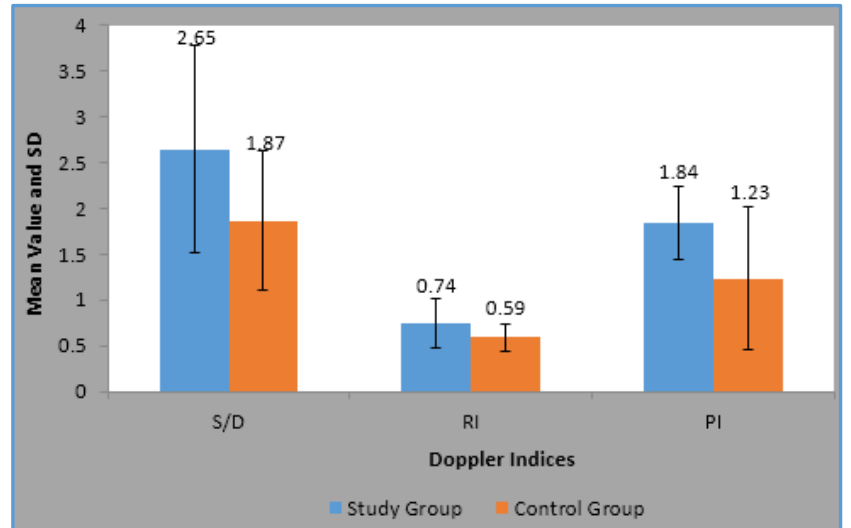

Graph 5. Distribution of Cases according to Doppler Indices of Umbilical Artery

\begin{tabular}{|c|c|c|c|c|}
\hline $\begin{array}{c}\text { Doppler } \\
\text { Indices }\end{array}$ & $\begin{array}{c}\text { Study } \\
\text { Group }\end{array}$ & $\begin{array}{c}\text { Control } \\
\text { Group }\end{array}$ & T-value & P-value \\
\hline S/D & $3.94 \pm 0.67$ & $1.80 \pm 0.79$ & 20.75 & $0.0001, \mathrm{~S}$ \\
\hline RI & $1.70 \pm 0.29$ & $0.77 \pm 0.21$ & 25.61 & $0.0001, \mathrm{~S}$ \\
\hline PI & $1.64 \pm 0.47$ & $0.89 \pm 0.31$ & 13.20 & $0.0001, \mathrm{~S}$ \\
\hline Table
\end{tabular}

Table 6. Distribution of Cases according to Doppler Indices of Middle Cerebral Artery

Table Number 6 shows distribution of cases according to Doppler indices of Middle cerebral artery, in which the mean value of S/D of study and control group cases are $3.94 \pm 0.67$ and $1.80 \pm 0.79$ respectively. Mean value of RI of study and control group cases are $1.70 \pm 0.29$ and $0.77 \pm 0.21$ respectively. Mean value of PI of study and control group cases are $1.64 \pm 0.47$ and $0.89 \pm 0.31$ respectively.

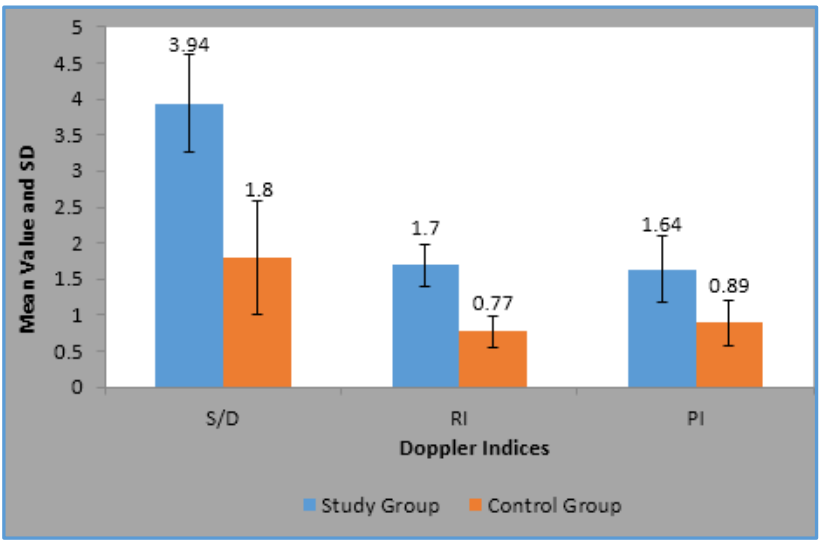

Graph 6. Distribution of Cases according to Doppler Indices of Middle Cerebral Artery

\begin{tabular}{|c|c|c|c|}
\hline Mode of delivery & Study Group & Control Group & «2-value \\
\hline NVD & $27(26.47 \%)$ & 67 (63.69\%) & \multirow{5}{*}{$\begin{array}{c}36.95 \\
p=0.0001, S\end{array}$} \\
\hline LSCS & $66(64.71 \%)$ & $28(27.45 \%)$ & \\
\hline PTVD & $6(5.88 \%)$ & $1(0.98 \%)$ & \\
\hline $\begin{array}{c}\text { Instrumental- } \\
\text { Vacuum/Forceps }\end{array}$ & $3(2.94 \%)$ & $6(5.88 \%)$ & \\
\hline Total & $102(100 \%)$ & $102(100 \%)$ & \\
\hline
\end{tabular}

Table Number 7 shows distribution of cases according to mode of delivery, in which $26.47 \%$ and $63.69 \%$ of the patients had NVD in study and control group respectively, $64.71 \%$ and $27.45 \%$ of the patients had LSCS in study and control group respectively, $5.88 \%$ and $0.98 \%$ of the patients had PTVD in study and control group respectively, 2.94\% and $5.88 \%$ of the patients had instrumental delivery in study and control group respectively.

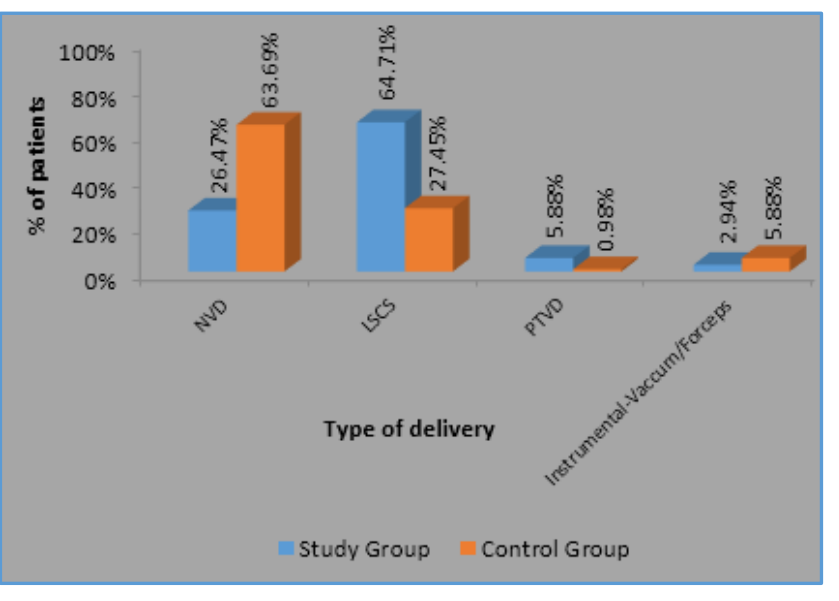

Graph 7. Distribution of Cases according to Mode of Delivery

\begin{tabular}{|c|c|c|c|}
\hline $\begin{array}{c}\text { Birth Weight } \\
\text { (Kg) }\end{array}$ & Study Group & Control Group & «2-value \\
\hline$<1.0$ & $0(0 \%)$ & $0(0 \%)$ & \multirow{7}{*}{$\begin{array}{c}42.82 \\
p=0.0001, S\end{array}$} \\
\hline $1-1.5$ & $10(9.80 \%)$ & $0(0 \%)$ & \\
\hline $1.5-2.5$ & $83(81.37 \%)$ & $54(52.94 \%)$ & \\
\hline$>2.5$ & $9(8.82 \%)$ & $48(47.06 \%)$ & \\
\hline Total & $102(100 \%)$ & $102(100 \%)$ & \\
\hline Mean \pm SD & $1.98 \pm 0.38$ & $2.49 \pm 0.25$ & \\
\hline Range & $1.28-2.58$ & $1.70-3.10$ & \\
\hline
\end{tabular}

Table Number 8 shows distribution of cases according to birth weight, in which no case of study and control group respectively belong to birth weight of $<1 \mathrm{~kg}, 0 \%$ and $9.80 \%$ cases of control and study group respectively belong to birth weight between $1-1.5 \mathrm{~kg}, 52.94 \%$ and $81.37 \%$ cases of control and study group respectively belong to birth weight between $1.5-2.5 \mathrm{~kg}, 47.06 \%$ and $8.82 \%$ cases of control and study group respectively belong to birth weight of $>2.5 \mathrm{~kg}$. The mean birth weight of study group is $1.98 \pm 0.38 \mathrm{~kg}$, while of control group is $2.49 \pm 0.25 \mathrm{~kg}$.

\begin{tabular}{|c|c|c|c|c|}
\hline $\begin{array}{c}\text { Apgar } \\
\text { Score }\end{array}$ & $\begin{array}{c}\text { Study } \\
\text { Group }\end{array}$ & $\begin{array}{c}\text { Control } \\
\text { Group }\end{array}$ & $\begin{array}{c}\text { T- } \\
\text { value }\end{array}$ & P-value \\
\hline $\begin{array}{c}\text { Apgar score at } \\
1 \text { min }\end{array}$ & $6.95 \pm 0.47$ & $7.16 \pm 0.52$ & 11.15 & $0.0001, \mathrm{~S}$ \\
\hline $\begin{array}{c}\text { Apgar score at } \\
5 \text { mins }\end{array}$ & $7.69 \pm 0.48$ & $8.12 \pm 0.50$ & 8.25 & $0.0001, \mathrm{~S}$ \\
\hline
\end{tabular}

Table 9. Comparison of Apgar Score in Study and Control Group

Table Number 9 shows comparison of Apgar score in study and control group cases. The mean value of Apgar score at $1 \mathrm{~min}$ for study and control group are $6.95 \pm 0.47$ and 7.16 \pm 0.52 respectively, while the mean value of Apgar score at 5 mins for study and control group are $7.69 \pm 0.48$ and $8.12 \pm$ 0.50 respectively. 


\begin{tabular}{|c|c|c|c|c|c|}
\hline \multirow{3}{*}{ Group } & \multirow{3}{*}{ Total } & \multicolumn{4}{|c|}{ Perinatal Outcome } \\
\hline & & \multicolumn{2}{|c|}{ Poor } & \multicolumn{2}{|c|}{ Fair } \\
\hline & & $\mathbf{N}$ & $\%$ & $\mathbf{N}$ & $\%$ \\
\hline \multicolumn{6}{|c|}{ Study Group } \\
\hline $\begin{array}{l}\text { Normal colour } \\
\text { Doppler }\end{array}$ & $\begin{array}{c}16 \\
(15.69 \%)\end{array}$ & 2 & 1.96 & 14 & 13.73 \\
\hline $\begin{array}{c}\text { Abnormal colour } \\
\text { Doppler }\end{array}$ & $\begin{array}{c}86 \\
(84.31 \%)\end{array}$ & 75 & 73.53 & 11 & 10.78 \\
\hline Total & $\begin{array}{c}102 \\
(100 \%)\end{array}$ & 67 & 65.69 & 35 & 34.31 \\
\hline \multicolumn{6}{|c|}{ Control Group } \\
\hline $\begin{array}{l}\text { Normal colour } \\
\text { Doppler }\end{array}$ & $\begin{array}{c}102 \\
(100 \%)\end{array}$ & 7 & 6.86 & 95 & 25.49 \\
\hline $\begin{array}{c}\text { Abnormal colour } \\
\text { Doppler }\end{array}$ & - & - & & - & \\
\hline Total & $\begin{array}{c}102 \\
(100 \%)\end{array}$ & 7 & 6.86 & 95 & 25.49 \\
\hline «2-value & \multicolumn{5}{|c|}{$40.69, p$-value $=0.0001, S$} \\
\hline Table 10. Peri & $\begin{array}{l}\text { al Outcon } \\
\text { Colour }\end{array}$ & & 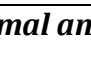 & & mal \\
\hline
\end{tabular}

Table number 10 shows comparison of Perinatal outcome in normal and abnormal colour Doppler. In study group, out of total patients $15.69 \%$ patients had normal colour Doppler among which $1.96 \%$ patients had poor perinatal outcome and remaining $13.73 \%$ had fair perinatal outcome. In study group out of total patients $84.31 \%$ patients had abnormal colour Doppler, among which $73.53 \%$ patients had poor perinatal outcome and remaining $10.78 \%$ had fair perinatal outcome. In control group all the colour Dopplers were normal, but $6.86 \%$ of the patients among them had poor perinatal outcome.

\section{DISCUSSION}

In the present study, mean age was 24.6 years for study group and 25.2 years for control group. Majority of the patients in study group had PIH alone or PIH with anaemia and second most common presentation is pregnancy with anaemia and Rh-ve blood group. In the present study S/D value of the uterine artery, umbilical artery showed significantly higher values in the study group as compared to the control group indicating increased peripheral resistance and consequently decreased diastolic flow leading to foetal compromise. The PI, RI and S/D ratios of MCA in high risk pregnancy group were significantly lower than that in the control group, indicating increase in the diastolic flow and cerebral vasodilatation and suggesting brain-sparing effect in the presence of foetal hypoxia due to placental insufficiency. In the present study, most of the women in the control group had Normal vaginal delivery (63.69\%), while in the study group majority of the women had LSCS (64.71\%), thus indicating increased operative intervention in the study group based on abnormal Doppler velocimetry. The mean birth weight and the Apgar score were lower in the study group as compared to the control group and the difference was highly significant $(\mathrm{p}<0.001)$.

In the present study, there was higher admission rate to the NICU $(66 \%)$ in the study group as compared to the control group (7\%). The uterine, umbilical and middle cerebral artery indices were abnormal in the group whose babies were admitted in the NICU as compared to those whose babies were not admitted. This implied poor perinatal outcome in the presence of abnormal indices and hence in the presence of foetal anoxia.
In 1994, RH Merchant et al(9) conducted a study on Colour Doppler evaluation of uteroplacentofoetal circulation in management of high-risk pregnancies, in which 75 high-risk pregnancies in whom colour Doppler evaluation of the uteroplacental circulation was determined and correlated with perinatal outcome. Out of the 75 foetuses studied, $33(44 \%)$ had abnormal Flow Velocity Waveforms and only $30.3 \%$ of these had an uncomplicated outcome as compared to $81 \%$ of those with normal flows. Similarly, in our study out of 102 patients of study group, $86(84.31 \%)$ patients had abnormal colour Doppler and amongst them 75 (87.2\%) had poor perinatal outcome.

Abhilasha Bansal et al(1) studied role of pan vessel Doppler Study in high-risk pregnancy and concluded that in women with abnormal Doppler indices there was high incidence of caesarean section (78\%), LBW, low Apgar score, higher admission rate to NICU (36\%) as compared to that of the control group which is in concordance with our study. In our study, $64.71 \%$ of the patients had LSCS and $81 \%$ of the babies had LBW.

Sharma Urmila et al(3) conducted a study in 2010 on triple vessel wave pattern by Doppler studies in normal and highrisk pregnancies and perinatal outcome and concluded that there was a high incidence of LSCS and NICU admissions in study group as compared to control group, which is similar to findings of our study.

In 2015, Apoorva Reddy et al(10) studied antepartum detection of the foetus at risk of death or compromise in utero. 40 pregnant women with a high-risk factor and 40 control cases were included in the study who were at 34 weeks of gestation. Study concluded that both uterine and umbilical artery Doppler velocities correlated well with the perinatal outcome, but abnormal uterine artery Doppler predicts adverse neonatal outcome better than foetal vessels. In our study, abnormal colour Doppler of all the three vessels correlated well with poor perinatal outcome.

\section{CONCLUSION}

There was high incidence of caesarean section due to foetal distress, low birth weight, increased incidence of nursery admissions and low Apgar score at 1 and 5 minutes with abnormal Doppler indices in the study group. Thus, the study concludes that colour Doppler study can be used as an adjunct in predicting high-risk pregnancies with adverse perinatal outcome.

\section{REFERENCES}

[1] Bansal A, Choudhary J, Gupta H. Role of Panvessel Doppler study in high risk pregnancy. IOSR Journal of Dental and Medical Sciences 2015;14(2),Ver. IV:90-3.

[2] Anshul D, Neelu S, Suneeta G. Significance of umbilical artery Doppler velocimetry in the perinatal outcome of the growth restricted foetuses. The Journal of Obstetrics and Gynecology of India 2010;60(1):38-43.

[3] Urmila S, Beena B. Triple vessel wave pattern by Doppler studies in normal and high risk pregnancies and perinatal outcome. J Obstet Gynecol India 2010;60(4):312-6.

[4] Fitzgerald DE, Drumm JE. Non-invasive measurement of human fetal circulation using ultrasound: a new method. A new method. Br Med J 1977;2(6100):14501. 


\section{Jemds.com}

[5] McCallum WD, Olson RF, Daigle RE, et al. Real time analysis of Doppler signals obtained from the fetoplacental circulation. Ultrasound Med 1977;3B:1361-4.

[6] Gómez O, Figueras F, Martínez JM, et al. Sequential changes in uterine artery blood flow pattern between the first and second trimesters of gestation in relation to pregnancy outcome. Ultrasound Obstet Gynecol 2006;28(6):802-8.

[7] Divon MY. Umbilical artery Doppler velocimetry: clinical utility in high risk pregnancies. Am J Obstet Gynecol 1996;174(1 Pt 1):10-4.

\section{Original Research Article}

[8] Miller J, Turan S, Baschat AA. Fetal growth restriction. Semin Perinatol 2008;32(4):274-80.

[9] Merchant RH, Lulla CP, Gharpure VP. Color Doppler evaluation of uteroplacentofetal circulation in management of high risk pregnancies. Indian Pediatrics 1994;31(5):511-7.

[10] Reddy A, Malik R, Mehra S, et al. Correlation of doppler studies at 34 weeks of gestation with perinatal outcome in high risk pregnancies. International Journal of Reproduction, Contraception, Obstetrics and Gynecology 2015;4(6):1894-9. 